\title{
Inhibition of interleukin-6 trans-signaling in the brain facilitates recovery from lipopolysaccharide- induced sickness behavior
}

\author{
Michael D Burton, Nathan L Sparkman and Rodney W Johnson*
}

\begin{abstract}
Background: Interleukin (IL)- 6 is produced in the brain during peripheral infection and plays an important but poorly understood role in sickness behavior. Therefore, this study investigated the capacity of soluble gp130 (sgp130), a natural inhibitor of the IL-6 trans-signaling pathway to regulate IL-6 production in microglia and neurons in vitro and its effects on lipopolysaccharide (LPS)-induced sickness behavior in vivo.
\end{abstract}

Methods: A murine microglia (BV.2) and neuronal cell line (Neuro.2A) were used to study the effects of stimulating and inhibiting the IL-6 signaling pathway in vitro. In vivo, adult (3-6 mo) BALB/c mice received an intracerebroventricular (ICV) injection of sgp130 followed by an intraperitoneal (i.p.) injection of LPS, and sickness behavior and markers of neuroinflammation were measured.

Results: Soluble gp130 attenuated IL-6- and LPS-stimulated IL-6 receptor (IL-6R) activation along with IL-6 protein release in both microglial (BV.2) and neuronal (Neuro.2A) cell types in vitro. Moreover, in vivo experiments showed that sgp130 facilitated recovery from LPS-induced sickness, and this sgp130-associated recovery was paralleled by reduced IL-6 receptor signaling, mRNA, and protein levels of IL-6 in the hippocampus.

Conclusions: Taken together, the results show that sgp130 may exert an anti-inflammatory effect on microglia and neurons by inhibiting IL-6 binding. These data indicate that sgp130 inhibits the LPS-induced IL-6 trans-signal and show IL-6 and its receptor are involved in maintaining sickness behavior.

\section{Background}

Peripheral infection stimulates production of pro-inflammatory cytokines including interleukin (IL)- $1 \beta$, IL-6, and tumor necrosis factor- $\alpha$ (TNF- $\alpha$ ). These cytokines use neural and humoral pathways to convey a message to the brain $[1,2]$. In the brain, the peripheral pro-inflammatory signal is mimicked by microglia, [3] and the resulting cytokines target neurons to elicit sicknessrelated behaviors that are typically adaptive [4]. However, excessive cytokine production by microglia is associated with prolonged sickness behavior [5-8], cognitive deficits [9-11], and affective disorders like anxiety and depression [12,13]. A recent study showed IL-6 knockout mice were refractory to LPS-induced increases of cytokines in the brain and cognitive deficits eluding to

\footnotetext{
* Correspondence: rwjohn@illinois.edu Laboratory of Integrative Immunology and Behavior, Animal Science Department, University of Illinois at Urbana-Champaign, Urbana, 7 Animal Sciences Lab 1207 W. Gregory Dr. Urbana IL 61801, USA
}

the potential permissive effects of IL- 6 during LPSinduced sickness [14].

The IL-6 receptor is activated through two separate, but related pathways; classical- and trans-signaling. Classical IL-6 receptor activation is facilitated through the IL6 ligand binding to its membrane-bound receptor. The receptor consists of two subunits: the IL-6 receptor-alpha chain (IL-6R), which binds IL-6, and the transmembrane signaling subunit, glycoprotein 130 (gp130), which is the intra-cellular signal transducer and is ubiquitously expressed. Both IL-6R and gp130 are cleaved immediately before the membrane spanning region by alternative splicing or shed by proteolytic enzymes to produce a soluble receptor located in extra-cellular matrix. It is important to note that the expression pattern of IL-6R is limited to few cells of the immune system and conservatively dispersed among other cell types, meaning classical signaling is highly conserved. In contrast, gp130 is ubiquitously expressed $[15,16]$. The basis of trans-signaling is soluble

\section{C) Biomed Central}


IL-6R (sIL-6R) binding to IL-6 in the extra cellular matrix to form a IL-6/sIL-6R complex, which has an increased binding affinity to membrane-bound gp130 subunits, resulting in the capability of IL- 6 production in any cell type that expresses gp130 [17,18].

Upon binding through either the classical or trans-signal, gp130 dimerizes and autophosphorylates, resulting in the activation of Janus kinase-1 and 2 (Jak1 \& Jak2). These tyrosine kinases phosphorylate the cytoplasmic region of gp130 creating recruitment sites for signal transducer and activation of transcription-3 (STAT3), a Src-homology-2 (SH2) domain-containing signaling molecule. Activated STAT3 forms a dimer, autophosphorylates, and translocates to the nucleus where it binds to enhancer elements of the IL- 6 promoter region. Thus the main consequence of both classical or transsignal IL-6 receptor action is to induce gene transcription and subsequent synthesis and secretion of IL-6, though trans-signaling allows this in many more cell types, due to the ubiquitous expression of gp130 [15]. sIL-6R and soluble gp130 (sgp130) have varying effects on circulating IL-6. Where sIL-6R acts as an agonist, sgp130 acts as a partial antagonist, or decoy receptor, by binding IL-6 or the IL-6/sIL-6R complex and prevents the binding of membrane-bound gp130 and further signal transduction [19].

The action of IL- 6 is heavily dependent on the location of the receptors and the cell types exposed to the cytokine. For instance, IL-6 binding to IL-6R located on $\mathrm{T}$-cells leads to the differentiation of stem line T-cells to helper $\mathrm{T}$ cells [20] whereas in the gastro-intestinal tract, IL- 6 and its receptors on epithelial cells contribute to peripheral disorders such as colitis and Crohn's disease [21]. However, studies examining IL-6 receptor signaling or trans-signaling in the CNS are limited and we are aware of no studies examining the extent to which IL-6 receptor signaling affects neuroinflammation and infection-related changes in behavior.

Therefore the purpose of this study was to assess classical and trans-signaling in neurons and microglia and determine if inhibiting IL-6 receptor signaling in the brain is sufficient to inhibit sickness behavior caused by peripheral infection. The important results showed treatment with sgp130 attenuated LPS-induced receptor activation and production of IL- 6 and enhanced recovery of sickness behavior. These findings suggest that inhibition of excessive production of IL- 6 through its signaling pathways during infection may be helpful in preventing behavioral deficits.

\section{Methods}

BV.2 microglial and Neuro.2A neuronal cell culture

The murine microglia cell line, BV.2 (a gift from Linda Van Eldik, Northwestern University, Evanston, IL) and neuronal Neuro.2A cells (purchased from ATCC) have been used as a model to investigate the neuroimmune system $[22,23]$. Cells were maintained in $150-\mathrm{cm}^{2}$ tissue culture flasks (BD Falcon, Franklin Lakes, NJ) in DMEM (Bio-Whittaker, Cambrex, MD) supplemented with 10\% FBS (Hyclone, Logan, UT), $200 \mathrm{mM}$ glutamine, and 100 units/ml penicillin/streptomycin (Invitrogen, Carlsbad, $\mathrm{CA})$ at $37^{\circ} \mathrm{C}$ in a humidified incubator under $5 \% \mathrm{CO}_{2}$. Confluent cultures were passed by trypsinization. Cells were centrifuged $\left(5 \mathrm{~min}\right.$ at $\left.27^{\circ} \mathrm{C}, 200 \times g\right)$, and culture medium was removed. In all experiments, cells were resuspended in DMEM supplemented with 10\% FBS and seeded in six-well plates (BD Falcon, Franklin Lakes, NJ) at a population of $3 \times 10^{5}-5 \times 10^{5}$ cells per well overnight at $37^{\circ} \mathrm{C}$ in a humidified incubator under $5 \% \mathrm{CO}_{2}$ before treatments. Cells were treated with sterile saline containing $0.1 \%$ BSA (vehicle), sIL-6R, or sgp130 (R\&D systems, Minneapolis, MN) for $1 \mathrm{~h}$ followed by treatment with recombinant IL-6 (R\&D systems, Minneapolis, MN) or Escherichia coli LPS (serotype 0127:B8 Sigma, St. Louis, MO), for $20 \mathrm{~min}$ or $3 \mathrm{~h}$, respectively.

\section{Flow cytometry}

Flow cytometric analysis of microglial and neuronal cell surface markers was performed as described previously, with a few modifications [24]. In brief, Fc receptors on BV.2 microglia cells were blocked with anti-CD16/CD32 antibody (eBioscience, San Diego, CA) in a PBS-1\% $\mathrm{BSA} /$ sodium azide solution, and incubated with antiCD126 PE and anti-CD130 APC or anti-TLR-4 PE (eBiosciences, San Diego, CA), fluorescently labeled isotype antibodies for PE and APC (eBiosciences, San Diego, CA) were used for controls. Expression of surface receptors was determined using a Becton-Dickinson LSR II Flow Cytometer (Red Oaks, CA). Fifty thousand events were collected and flow data were analyzed using FCS Express software (De Novo Software, Los Angeles, CA).

\section{Animals and surgery}

Adult (3-6 months) male BALB/c mice obtained from our in-house breeding colony were used in all experiments. Mice were housed in polypropylene cages and maintained at $21^{\circ} \mathrm{C}$ under a reverse-phase $12 \mathrm{~h}$ lightdark cycle (lights off at 07:00) with ad libitum access to water and rodent chow.

\section{Surgery}

Intracerebroventricular (ICV) cannulation was performed under aseptic conditions as described previously [25]. In brief, mice were deeply anesthetized with an intraperitoneal (i.p.) injection of ketamine and xylazine (100 and $10 \mathrm{mg} / \mathrm{kg}$, respectively) and the surgical site was shaved and sterilized. They were positioned in a stereotaxic instrument (David Kopf Instruments, 
Tujunga, CA) so that the frontal and parietal bones of the skull were parallel to the surgical platform. An incision roughly $1.5 \mathrm{~cm}$ in length was made on the cranium to reveal the bregma and a 26-gauge stainless steel cannula (Plastics One, Roanoke, VA) was placed in the right lateral cerebral ventricle according to predetermined stereotaxic coordinates (lateral $1.6 \mathrm{~mm}$ and antero-posterior $1 \mathrm{~mm}$ to the bregma, and horizontal 2 $\mathrm{mm}$ from the dura mater). The cannula was secured using two adjacent stainless steel screws and cranioplastic cement (Plastics One, Roanoke, VA). A dummy cannula (Plastics One, Roanoke, VA) was inserted in the guide cannula to prevent occlusion and infection. Mice were injected subcutaneously with buprenorphine $(0.05$ $\mathrm{mg} / \mathrm{kg}$ ) following surgery and then again 8-12 $\mathrm{h}$ later to aid with any post-operative discomfort. Mice were provided a minimum of seven days to recover from any discomfort or weight loss before any treatment or behavioral test. Accurate placement of the cannula was confirmed by allowing $2 \mu \mathrm{l}$ of sterile saline to flow via gravity into the lateral ventricle. If cannula placement could not be confirmed, the animal was excluded from the study. All procedures were in accordance with the National Institutes of Health Guidelines for the Care and Use of Laboratory Animals and were approved by the University of Illinois Institutional Animal Care and Use Committee.

\section{Animal studies}

Mice were handled 1-2 min each day for seven days before experimentation to acclimate them to routine handling. On test day, animals were injected ICV with sterile saline containing $0.1 \%$ BSA (vehicle) or $100 \mathrm{ng}$ sgp130 dissolved in $2 \mu \mathrm{l}$ vehicle. At the same time as the ICV injection, mice were injected i.p. with sterile saline or LPS $(0.33 \mathrm{mg} / \mathrm{kg}$ BW or $10 \mu \mathrm{g}$, serotype 0127 : B8, Sigma, St. Louis, Mo.). The LPS dosage was selected because it elicits a proinflammatory cytokine response in the brain, which results in mild transient sickness behavior in adult mice [26]. Tests were conducted during the dark phase (between 07:00 and 19:00) of the light/dark cycle under infrared lighting to aid video recording. Baseline behavior was taken just before treatment administration $(0 \mathrm{~h})$ and 4,8 , and $24 \mathrm{~h}$ afterwards.

To measure changes in cytokines and signaling molecules, mice not exposed to the behavior paradigms were injected ICV with vehicle or sgp130 (100 ng) and i.p. with sterile saline or LPS $(10 \mu \mathrm{g})$ and killed $8 \mathrm{~h}$ later by $\mathrm{CO}_{2}$ asphyxiation. Blood samples were collected via cardiac puncture into EDTA-coated syringes to obtain plasma, and the brain was rapidly removed and dissected to obtain hippocampal tissue. Plasma and hippocampal tissue were snap-frozen in liquid nitrogen and stored at $-80^{\circ} \mathrm{C}$ until later analysis.

\section{Behavioral tests}

\section{Social exploratory behavior}

To assess motivation to engage in social exploration, a novel male juvenile conspecific (20-30 days old) from our in-house colony was introduced into the test subject's home cage for a $7 \mathrm{~min}$ period. Mice were video recorded, and the duration engaged in social investigation was determined from the video records by a trained observer who was blind to experimental treatments. Social behavior was determined as the amount of time that the experimental animal spent investigating (e.g. trailing, anogenital sniffing) the juvenile. Baseline social behavior was determined for all experimental treatments at the $0 \mathrm{~h}$, for a $7 \mathrm{~min}$ period. Statistical analysis revealed there were no significant differences between treatment groups at baseline. The results are expressed as percent depression in time engaged in social behavior compared to respective baseline measures.

\section{Western immunoblotting}

To assess IL-6 receptor signaling in CNS cells in vitro, BV.2 and Neuro.2A cells were harvested and in vivo, mouse hippocampal tissue was unthawed, and lysed in ice cold lysis buffer containing: $100 \mathrm{mM}$ HEPES (7.5 pH), $150 \mathrm{mM} \mathrm{NaCl}, 1 \%$ Nonidet P-40 (U.S. Biological, Swampscott, MA), 2 mM EGTA, 2 mM Sodium Orthovanadate, Protease Inhibitor cocktail (100 mM EDTA, 1 $\mu \mathrm{g} / \mathrm{mL}$ AEBSF, Bestatin, Pepstatin A, Leupeptin, Aprotinin, and E-64), and $1 \mathrm{mM}$ PMSF and centrifuged at $11000 \times \mathrm{g}$ for $10 \mathrm{~min}$ at $4^{\circ} \mathrm{C}$ to remove all cellular debris. Protein concentration was determined using the BCA Protein Assay according to the manufacturer's protocol (Bio-Rad, Hercules, CA). Lysate concentration was then normalized and denatured in SDS/PAGE buffer at $95^{\circ} \mathrm{C}$ and stored at $-20^{\circ} \mathrm{C}$ until use. All lysates were electrophoresed and separated on a 7.5\% SDS-PAGE gel, and transferred onto nitrocellulose membranes (GE Healthcare, Minneapolis, MN). The membranes were blocked with $5 \%$ non-fat milk and incubated with anti-phosphorylated STAT3 (tyr-705) antibody (Cell Signaling, Danvers, MA) overnight at $4^{\circ} \mathrm{C}$. After incubation with an HRPconjugated secondary antibody, the protein bands were detected with a chemiluminescenct substrate (Cell Signaling, Danvers, MA) and Bio-Max film (Eastman Kodak Company, Rochester, NY). For detection of total STAT3 protein, the membranes were stripped with stripping buffer (2\% SDS, $6.25 \mathrm{mM}$ Tris. HCL (6.8 pH), 0.70\% $\beta$-ME) followed by overnight incubation with anti-STAT3 antibody (Cell Signaling, Danvers, MA) at $4^{\circ} \mathrm{C}$. Immunoblot results were quantified using ImageJ 1.41 software $(\mathrm{NIH})$.

\section{Cytokine detection in cell supernatant, hippocampus, and plasma}

Hippocampal tissue was lysed in ice cold lysis buffer and protein concentrations were determined using the 
BCA protein assay according to manufacturer's protocol. For hippocampal tissue, the antibodies and standards for the IL- 6 ELISA were used according to the description by the manufacturer (eBiosciences San Diego, CA). Cell supernatants and plasma samples were assayed for IL-1 $\beta$, TNF- $\alpha$, IL- 6 , and the anti-inflammatory cytokine IL-10, using multiplexed bead-based immunoassay kits combined with a Cytokine Reagent kit as described by the manufacturer (Bio-Rad, Hercules, CA).

\section{Cytokine mRNA measurement by quantitative real-time PCR}

Total RNA from hippocampus was isolated using the Tri Reagent protocol (Sigma, St. Louis, MO.) A QuantiTect Reverse Transcription Kit (Qiagen, Valencia, CA) was used for cDNA synthesis with integrated removal of genomic DNA contamination according to the manufacturer's protocol. Quantitative real time PCR was performed using the Applied Biosystems (Foster, CA) Assay-on Demand Gene Expression protocol as previously described [27]. In brief, cDNA was amplified by PCR where a target cDNA (IL-6, Mm00446190_m1; IL$1 \beta$, Mm00434228_m1; TNF- $\alpha$, Mm00443258_m1; IL-10, Mm00439616_m1, IL-6R, 00439653_m1; and gp130, mM00439665_m1) and a reference cDNA (glucose-3 phosphate dehydrogenase, Mm99999915_g1) were amplified simultaneously using an oligonucleotide probe with a 5' fluorescent reporter dye (6-FAM) and a 3' quencher dye (NFQ). PCR reactions were performed in triplicate under the following conditions: $50^{\circ} \mathrm{C}$ for 2 $\min , 95^{\circ} \mathrm{C}$ for $10 \mathrm{~min}$, followed by 40 cycles of $95^{\circ} \mathrm{C}$ for $15 \mathrm{sec}$ and $60^{\circ} \mathrm{C}$ for $1 \mathrm{~min}$. Fluorescence was determined on an ABI PRISM 7900HT-sequence detection system (Perkin Elmer, Forest City, CA). Data were analyzed using the comparative threshold cycle $(\mathrm{Ct})$ method, and results are expressed as fold difference.

\section{Statistical analysis}

All data were analyzed using Statview and Statistical Analysis System software (SAS Inst., Cary, NC). Behavioral data were subjected to a three-way ANOVA $(\operatorname{sgp} 130 \times$ LPS $\times$ Time $)$ using repeated measures in which Time $(0,4,8$, and $24 \mathrm{~h})$ was a within subjects measure, and sgp130 and LPS were between subjects measures. Cytokine mRNA and protein levels were analyzed using a two-way ANOVA (sgp130 × LPS). Phosphorylation of STAT3 levels were analyzed using a twoway ANOVA (sIL-6R or sgp130 × LPS). Post hoc Student's $t$ test of least square means was used to determine if treatment means were significantly different from one another $(P<0.05)$. All data are presented as mean \pm SEM.

\section{Results}

IL-6 and LPS induce STAT3 phosphorylation in microglia and neurons

To verify the presence of the subunits involved in IL-6 and LPS signaling, the cell surface expression of IL-6R, gp130, and TLR-4 on BV.2 and Neuro.2A cells was examined. Figure $1 \mathrm{~A}$ shows more than $50 \%$ of the microglial BV.2 cells expressed gp130 while nearly $90 \%$ expressed IL-6R; approximately $50 \%$ of the BV.2 cells expressed both IL-6R and gp130. In contrast, about $90 \%$ of the Neuro.2A cells expressed gp130, 3\% expressed IL$6 \mathrm{R}$, and $3 \%$ co-expressed IL-6R and gp130. Approximately $80 \%$ of the BV.2 cells expressed TLR-4 compared to $30 \%$ of the Neuro.2A cells (Figure 1B). Although IL-6 can activate multiple transcription factors (e.g., STAT3, AP-1, CREB), in CNS cells activation of the IL-6 receptor upregulates STAT3 phosphorylation $[15,28,29]$. Thus, the capacity of IL- 6 to induce the phosphorylation of STAT3 in BV.2 and Neuro.2A cell cultures was examined. Figure 2 shows that IL- 6 at a higher concentration $(50 \mathrm{ng} / \mathrm{mL})$ increased phosphorylated STAT3 similarly in microglia $[\mathrm{F}(1,48)=12.515, \mathrm{p}<0.001]$ and neurons $[\mathrm{F}(1,50)=11.115, \mathrm{p}<0.01]$. However, at a lower concentration (10 ng/mL), IL-6 only increased STAT3 phosphorylation in microglia $[\mathrm{F}(1,14)=37.384$, $\mathrm{P}<.001$ ], which is consistent with the greater proportion of these cells that expressed IL-6R. These findings suggest that classic and trans-signaling can occur on both neurons and microglia, although neurons may be more readily regulated through the mechanism of trans-signaling since gp130 is highly expressed on this cell type.

\section{IL-6 trans-signaling in microglia and neurons}

Previous studies have shown that gp130 is expressed constitutively on all cell types [30,31] and this expression facilitates trans-signaling in the presence of IL-6 and sIL-6R $[17,18,32]$. Figure $3 \mathrm{~A}$ shows that pretreatment of microglia and neurons with sIL-6R increased IL-6-induced STAT3 phosphorylation $[\mathrm{F}(2,55)=4.963, \mathrm{p}<0.01]$ and $[\mathrm{F}(2,53)$ $=7.642, \mathrm{p}<0.001]$, respectively. Consistent with the increase in STAT3 phosphorylation, a sIL-6R $\times$ LPS interaction was evident whereby sIL-6R upregulated LPSinduced IL-6 production in microglia $[\mathrm{F}(2,55)=3.419, \mathrm{p}$ $<0.05]$, and neurons $[\mathrm{F}(2,53)=3.619, \mathrm{p}<0.04]$. Although not statistically significant, there was some constitutive STAT3 phosphorylation and IL-6 expression in samples pretreated with sIL-6R (Figure 3A and 3B).

\section{sgp130 attenuated IL-6R activation in microglia and neurons}

We next investigated the ability of sgp130 to alter phosphorylation of STAT3 and expression of IL-6. A sgp130 $\times$ LPS interaction revealed that pretreatment of BV.2 


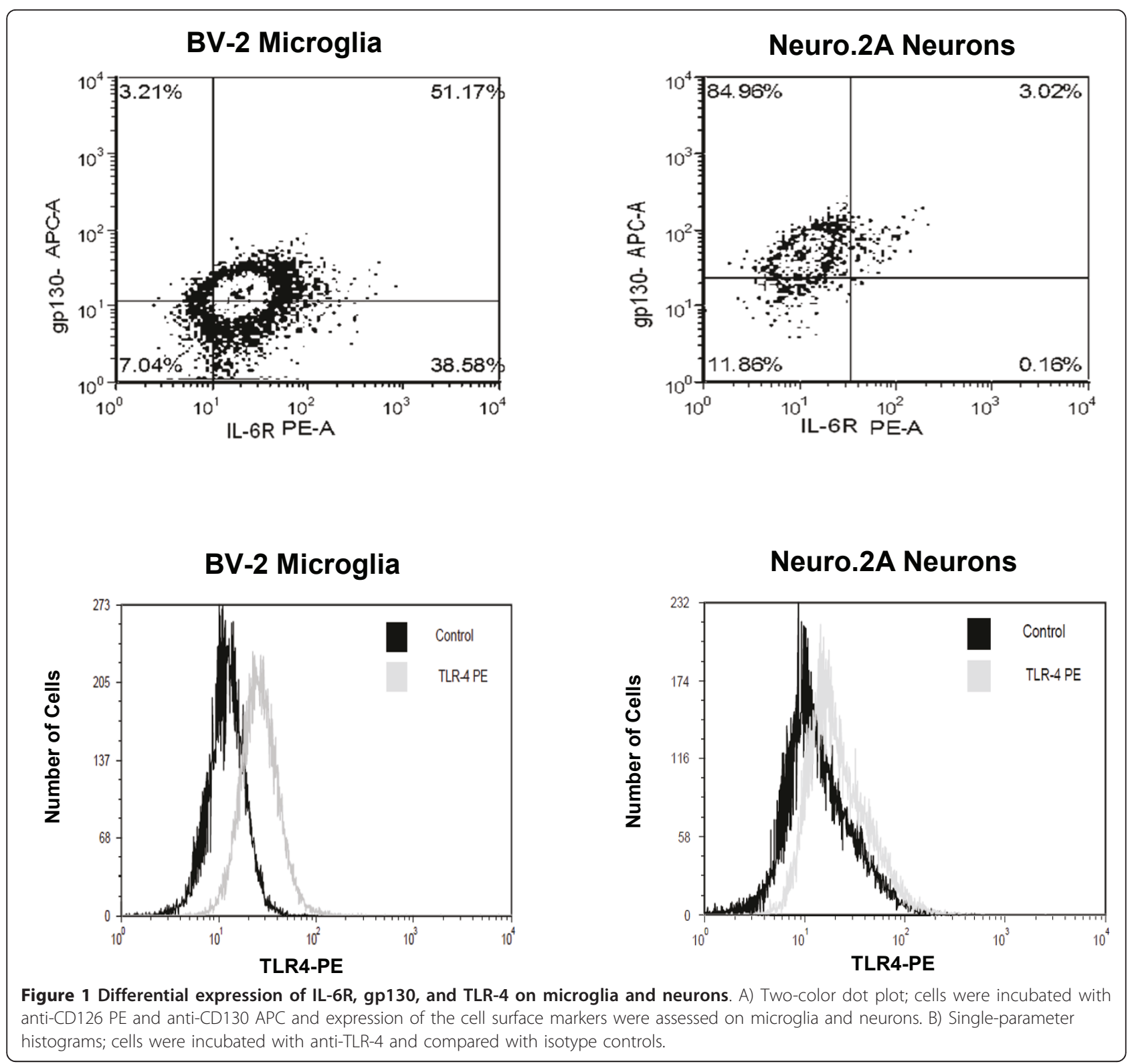

microglial and Neuro.2A neuronal cells with sgp130 decreased LPS-induced activation of STAT3 $[\mathrm{F}(2,59)=$ $3.736, \mathrm{p}<0.03]$ and $[\mathrm{F}(2,60)=4.385, \mathrm{p}<0.02]$, respectively and inhibited LPS-induced IL- 6 production in both BV.2 [F $(2,59)=3.253, \mathrm{p}<0.05]$ and Neuro.2A cells $[\mathrm{F}(2,60)=3.680, \mathrm{p}<0.04]$ (Figure $4 \mathrm{~A}$ and $4 \mathrm{~B}$, respectively). These data demonstrate that sgp130 inhibits LPS-induced IL-6 production in microglia and neurons. The LPS-induced secretion of IL- $1 \beta$, TNF- $\alpha$, and IL-10 was not affected by sgp130 (data not shown).

\section{sgp130 inhibits LPS-induced sickness behavior}

Brain microglia and neurons produce inflammatory cytokines, including IL-6, that induce sickness behavior.
Given the in vitro results, we investigated the effect of centrally administered sgp130 on LPS-induced sickness behavior. Social exploratory behavior was used to measure sickness. Three-way ANOVA of social behavior revealed a significant LPS $\times$ time $\times$ sgp130 interaction $[\mathrm{F}(3,48)=6.280, \mathrm{P}<0.01]$. As expected, LPS treatment decreased social exploratory behavior in a time-dependent manner $[\mathrm{F}(3,48)=15.896, \mathrm{p}<0.001]$. LPS induced transient sickness, as the behavior of mice given LPS returned to baseline by $24 \mathrm{~h}$ post-injection (Figure 5 ). However, behavior of mice treated ICV with sgp130 prior to LPS returned to normal sooner. That sgp130 did not inhibit LPS-induced sickness behavior at 2 or 4 $\mathrm{h}$ after LPS treatment but did later, suggests the IL-6 


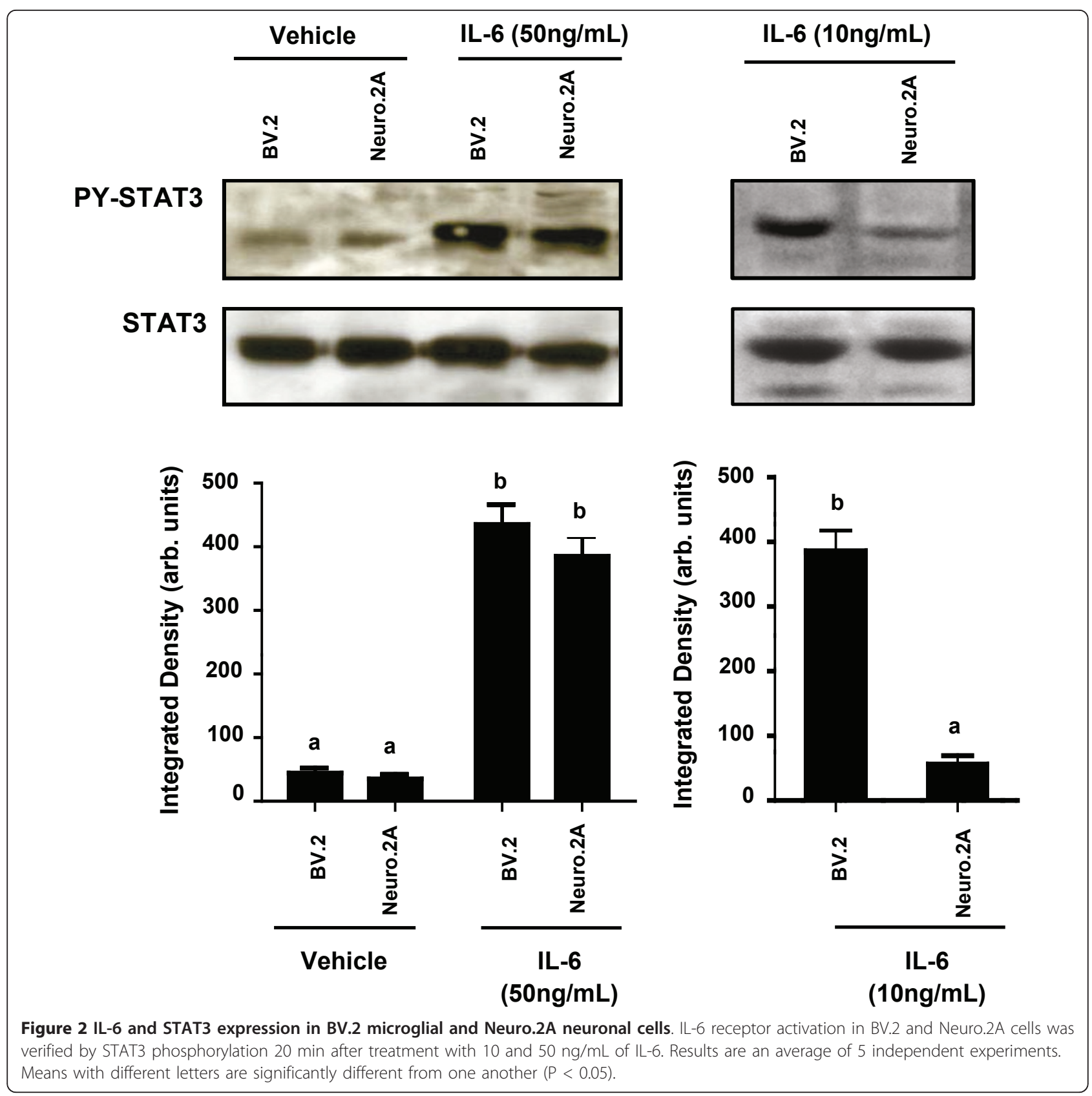

trans-signaling pathway is important for maintaining sickness behavior but not for its induction.

sgp130 attenuated STAT3 phosphorylation and IL-6 gene expression and protein in the brain

Because sgp130 inhibited LPS-induced sickness behavior $8 \mathrm{~h}$ post-injection, hippocampal tissue and plasma was collected from a separate group of sgp130- and LPStreated mice at the $8 \mathrm{~h}$ time point to assess STAT3 phosphorylation and IL-6 expression. Similar to the in vitro results, i.p. LPS upregulated STAT3 phospho-protein in the hippocampus $[F(1,19)=369.003$, p <
0.0001]. There was a sgp $130 \times$ LPS interaction $[F(1,19)$ $=22.293, \mathrm{P}<0.001]$ whereby STAT3 phosphorylation was blunted when mice were given ICV sgp130 (Figure $6 \mathrm{~A})$. There was also a significant sgp130 $\times$ LPS interaction $[\mathrm{F}(1,19)=5.108, \mathrm{P}<0.02]$ whereby $\operatorname{sgp} 130$ decreased the amount of LPS-induced IL- 6 mRNA in the hippocampus, although it did not significantly affect IL-1 $\beta$ or TNF- $\alpha$ mRNA (Figure $6 \mathrm{~B}$ ). To determine if the effect of sgp130 was also apparent at the protein level, LPS-induced IL- 6 protein was measured. As expected, LPS alone increased IL- 6 protein in the hippocampus; however, a sgp130 $\times$ LPS interaction $[F(1,21)=42.921$, 
BV.2 Microglia

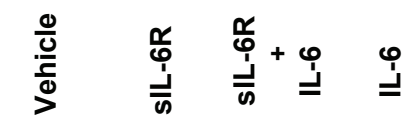
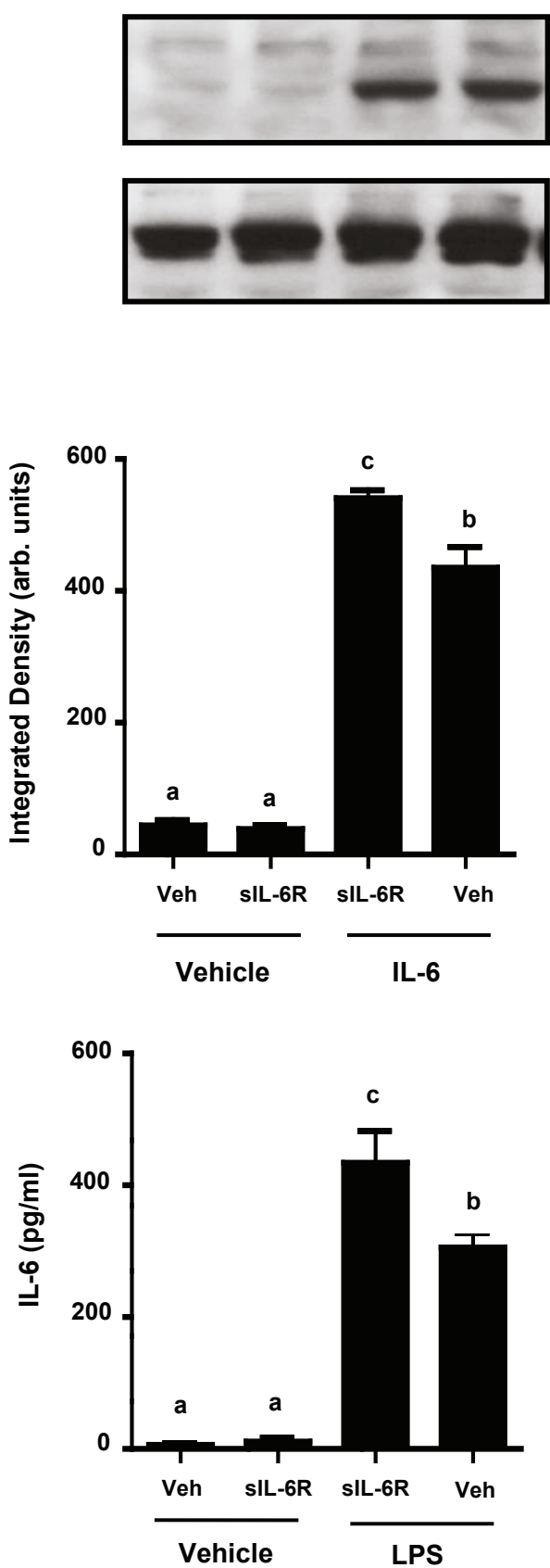

Neuro.2A Neurons

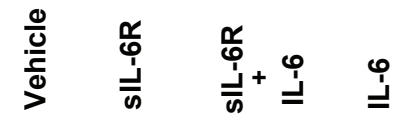

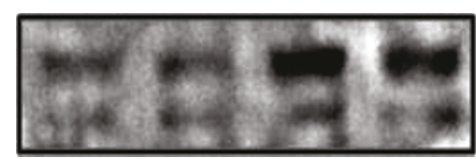

PY-STAT3

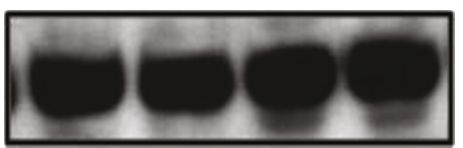

STAT3
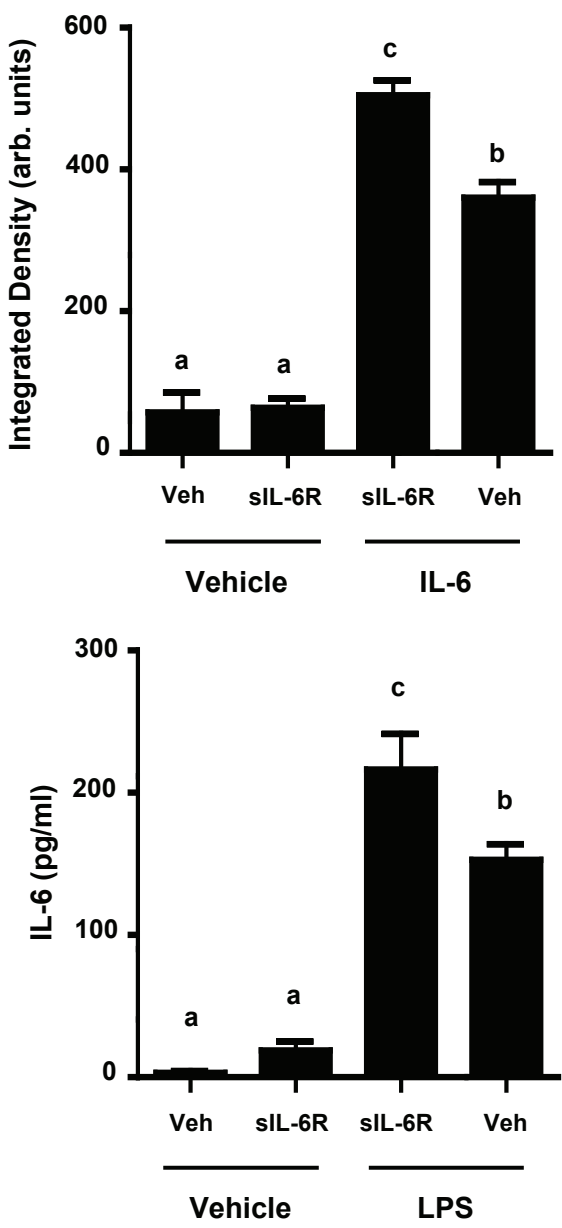

Figure 3 IL-6 trans-signaling in BV.2 microglia and Neuro.2A cells. BV.2 and Neuro2A cells were pre-treated for $1 \mathrm{~h} \mathrm{with} 25 \mathrm{ng} / \mathrm{mL} \mathrm{slL}-6 \mathrm{R}$ and A) IL-6-induced STAT3 phosphorylation and B) LPS-induced IL-6 protein secretion were measured at 20 min and $3 \mathrm{~h}$, respectively. Results are an average of 5 independent experiments. Means with different letters are significantly different from one another $(P<0.05)$. 


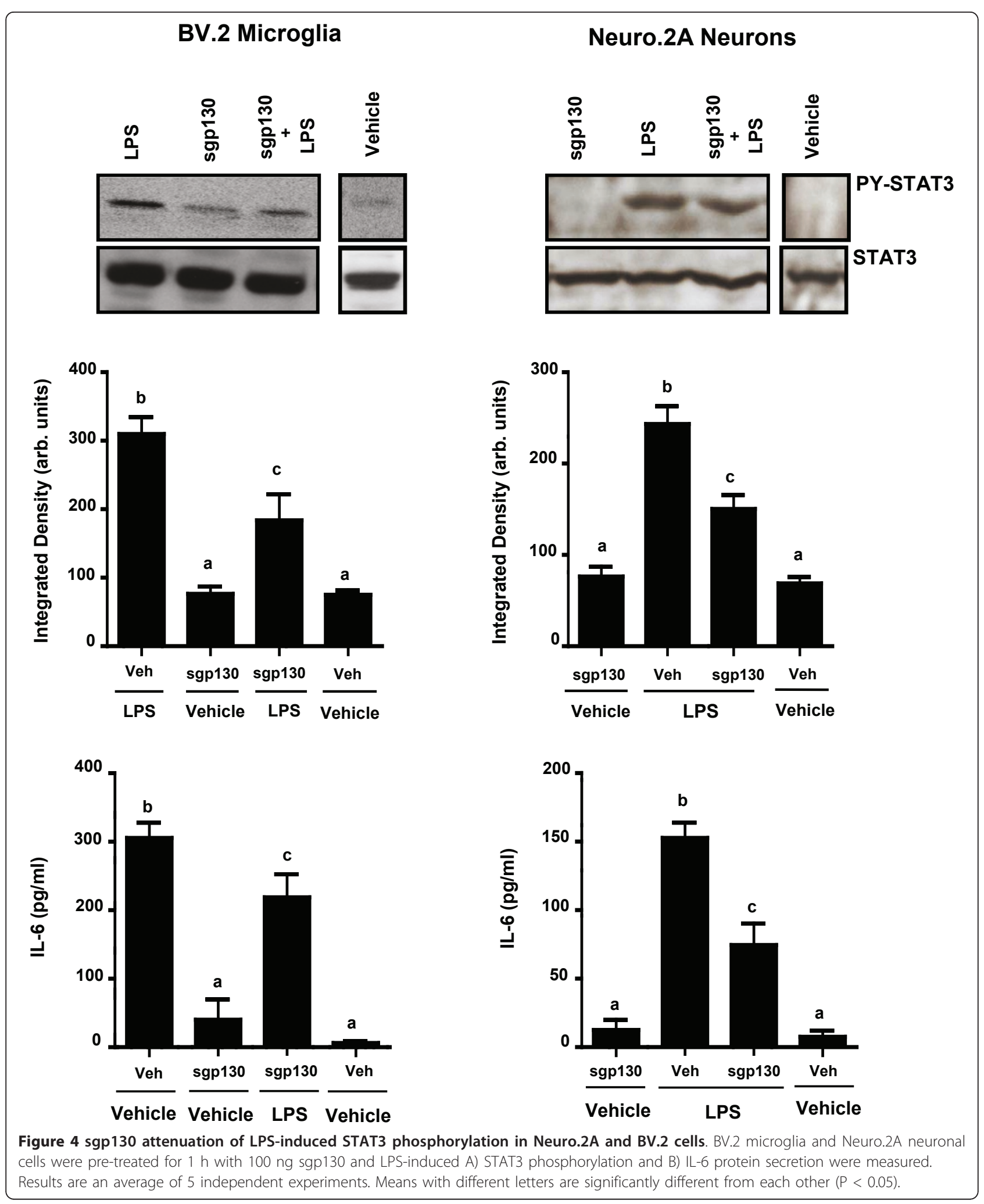




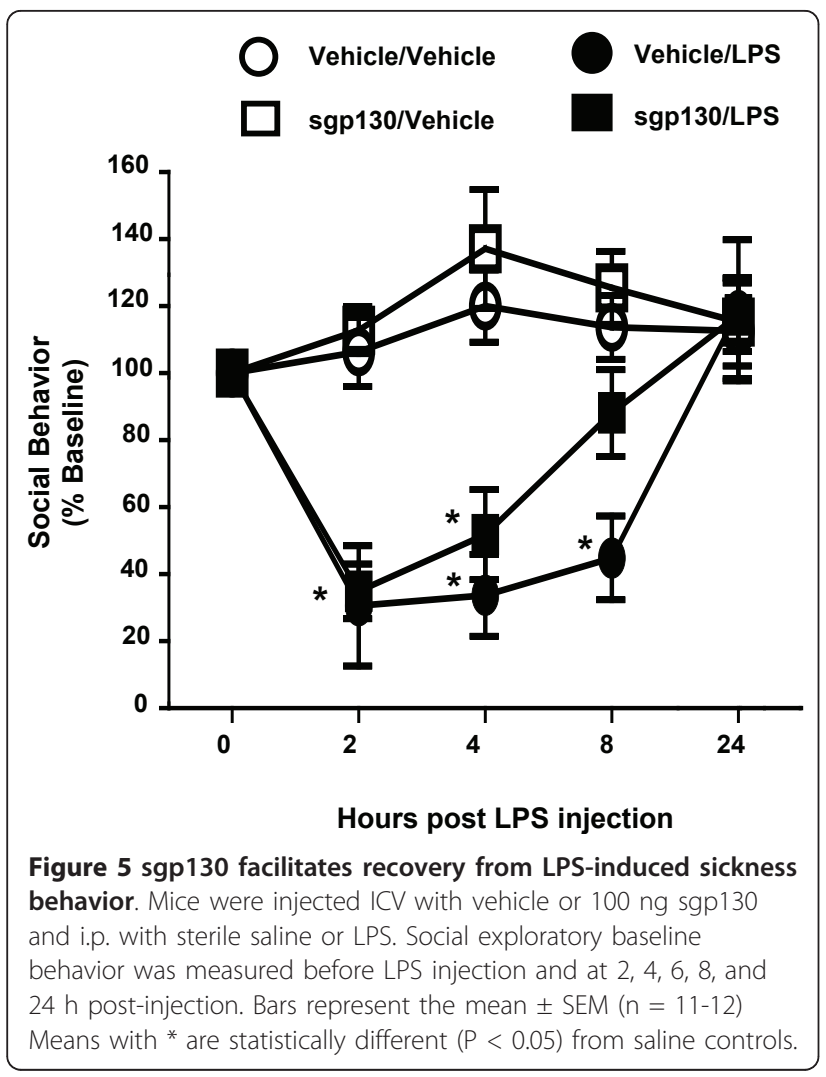

$\mathrm{p}<0.0001]$ indicated that co-administration of sgp130 inhibited the LPS-induced increase in IL-6 (Figure 6C). Taken together, these results show that sgp130-related changes in LPS-induced social behavior are paralleled by sgp130-associated changes in the brain.

To assess the effect of ICV sgp130 on the peripheral cytokine response to i.p. LPS, plasma was assayed for IL-1 $\beta$, IL-6, IL-10, and TNF- $\alpha$. Plasma levels of all four cytokines was increased after LPS treatment and this was not affected by sgp130 (Table 1), suggesting ICV sgp130 acts locally in the brain.

\section{Discussion}

Bi-directional communication between the periphery and the brain is important for the appropriate response to an immune stimulus [33]. During peripheral infection, pro-inflammatory cytokines are produced in the brain and play a role in adaptive sickness behavior. However, an excessive cytokine response in the brain is associated with prolonged sickness behavior [5-8], cognitive deficits [9-11], and increased anxiety [12,13]; and the specific role of IL- 6 has not been extensively studied. We investigated the capacity of sgp130 to block IL-6 production in microglia and neurons in vitro and explored the effects of sgp130 on LPS-induced sickness behavior in vivo. In vitro, sgp130 attenuated LPS-stimulated IL-6R activation along with IL-6 protein release in both microglial (BV.2) and neuronal (Neuro.2A) cell types. Moreover, in vivo experiments showed that ICV sgp130 facilitated recovery from LPS-induced sickness, and this sgp130-associated recovery was paralleled by reduced IL-6 mRNA and protein levels in the hippocampus.

The present study demonstrates that murine microglia and neurons have the potential to produce IL- 6 through both a classic and trans-signaling pathway. In two-color flow cytometry experiments, we showed that BV.2 and Neuro.2A cells expressed both gp130 and IL-6R on their cell surface, though expression differed in each cell type. The findings indicate that classic and trans-signaling are important on both neurons and microglia, though neurons may be more readily regulated through the mechanism of trans-signaling. Previous studies report that the presence of the sIL-6R elicits an exaggerated production of IL-6 protein $[32,34,35]$. Consistent with these reports, we found that pretreatment of sIL-6R led to an IL-6- and LPS-induced increase of IL-6 protein in microglia and neurons. This response is presumably elicited by the ligand and soluble receptor forming a sIL6R/IL-6 complex. This complex has the ability to bind to the gp130 transmembrane receptor signal transducer and activate intracellular signals that produce IL- 6 in any cell type via this trans-signaling mechanism.

LPS binds TLR-4, which we confirmed was present on both microglia and neurons. Upon binding, LPS induces upregulation of the NF- $\kappa \mathrm{B}$ transcription factor that binds promoter regions to stimulate the production of IL-6 along with a milieu of other cytokines (e.g. IL-1 $\beta$, TNF- $\alpha$, and IL-10) [36]. Soluble gp130 inhibits IL-6 trans-signaling but also regulates IL- 6 related cytokines oncostatin M (OSM) and leukemia inhibitory factor (LIF). However, sgp130 has a much lower affinity for OSM and LIF than for the IL-6/sIL-6R complex [19] and would not be expected to affect either cytokine at the dose used here $[19,37]$. Therefore, using sgp130 allowed us to investigate the effects of IL- 6 after LPS treatment, while leaving all other cytokines unaffected.

Successful activation of the IL-6R is noted by the dimerization of gp130, resulting in an intracellular cascade that forms recruitment sites for STAT3 in the cytoplasmic region. STAT3 homodimerizes, autophosphorylates, then translocates to the nucleus and binds to enhancer elements of IL-6 to induce gene transcription. Here, STAT3 was upregulated in response to both IL- 6 and LPS in BV. 2 and Neuro.2A cells and pretreatment with sIL-6R led to an increased IL-6- and LPSinduced STAT3 phosphorylation. However, when pretreated with sgp130, IL-6 and LPS-stimulated BV.2 and Neuro.2A cells displayed a decrease in STAT3 phosphorylation. These data agree with other studies using sgp130 to inhibit IL-6 signaling in peripheral models of 

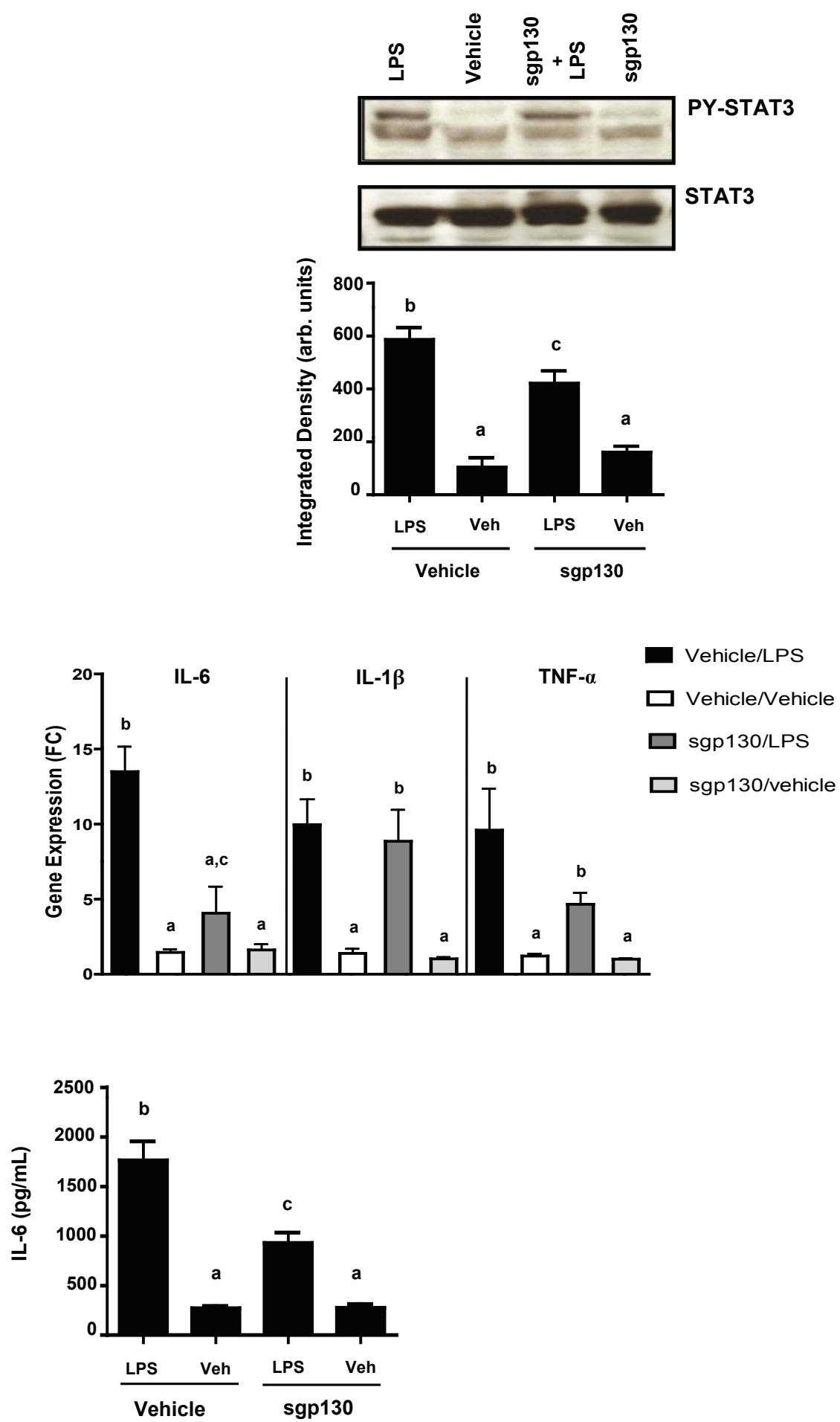

Figure 6 sgp130 reduces IL- 6 receptor activation, gene expression, and protein secretion in vivo. Hippocampal tissue was collected $8 \mathrm{~h}$ after ICV sgp130 and i.p. LPS and assayed for A) STAT3 phosphorylation, B) mRNA levels of IL-6,IL-1 $\beta$, and TNF- $\alpha$, C) and IL-6 protein. sgp130 reduced LPS-induced STAT3 phosphorylation, mRNA levels of IL-6, but not IL-1 $1 \beta$ or TNF- $\alpha$, and IL-6 protein in the hippocampus. Bars represent the mean \pm SEM $(n=8-9)$ Means with different letters are statistically different from each other $(P<0.05)$. 
Table 1 Plasma cytokines $8 \mathrm{~h}$ after sgp130 and LPS

\begin{tabular}{|c|c|c|c|c|c|c|c|}
\hline & \multicolumn{2}{|c|}{ Vehicle (ICV) } & \multicolumn{2}{|c|}{ sgp130 (100 ng) (ICV) } & \multicolumn{3}{|c|}{$\mathrm{p}<0.05$ interaction } \\
\hline & Saline (i.p.) & LPS $(10 \mu g)$ (i.p.) & Saline (i.p.) & LPS $(10 \mu g)$ (i.p.) & sgp130 & LPS & sgp130 $\times$ LPS \\
\hline $\mathrm{IL}-1 \beta$ & $206.82 \pm 86.19$ & $1113.12 \pm 24.48$ & $191.10 \pm 85.12$ & $1543 \pm 695.96$ & 0.537 & $0.009^{*}$ & 0.513 \\
\hline IL-6 & $142.87 \pm 117.79$ & $2873.03 \pm 994.50$ & $96.50 \pm 8.41$ & $2682.06 \pm 669.86$ & 0.820 & $0.001^{*}$ & 0.955 \\
\hline TNF- $\alpha$ & $325.89 \pm 54.60$ & $987.55 \pm 104.77$ & $322.95 \pm 73.31$ & $947.93 \pm 119.32$ & 0.829 & $<0.0001^{*}$ & 0.852 \\
\hline $\mathrm{IL}-10$ & $56.39 \pm 23.01$ & $407.34 \pm 92.56$ & $46.72 \pm 11.47$ & $447.22 \pm 174.13$ & 0.764 & $0.002^{*}$ & 0.719 \\
\hline
\end{tabular}

inflammation such as arthritis, peritonitis, and colitis [38-40]. To our knowledge, this is the first study to report that pretreatment with sgp130 attenuated LPSinduced IL-6 protein secretion in CNS-derived cells.

LPS activation of the peripheral innate immune system stimulates a robust secretion of inflammatory cytokines through the NF- $\kappa \mathrm{B}$ pathway and these cytokines are relayed to the CNS via vagal nerve afferents, and humoral and diffusive pathways $[1,2]$. Once in the brain this inflammatory signal is mimicked by innate immune cells $[3,41,42]$ and targets neurons which elicit a sickness behavior response that includes general malaise, decreased activity, decreased social interaction, decreased food and water intake (weight loss), and sleep dysregulation $[4,33,43]$. We therefore investigated the effects of ICV sgp130 in vivo and hypothesized that, given the role of IL-6 in neuroinflammatory responses; it would attenuate LPS-induced sickness behavior and IL-6 production. Here we show that sgp130 was effective in facilitating the recovery from LPS-induced social exploratory behavior as early as $8 \mathrm{~h}$ in mice. In addition to facilitating recovery from LPS, sgp130 attenuated receptor activation, gene expression, and production of IL-6 in adult mice $8 \mathrm{~h}$ after LPS injection. Consistent with previous studies $[24,26,44,45]$, a reduction in brain cytokines did not prevent the initial induction of LPSinduced sickness behavior seen at 2-4 h post-injection, but rather facilitated the recovery from sickness starting at the $8 \mathrm{~h}$ time point $[32,34,35]$. In this model, the inability of sgp130 to block the onset of sickness behavior can be attributed to the fact that LPS induces multiple proinflammatory cytokines that have redundant properties and inhibition of a single cytokine is not sufficient to block the initial sickness. It is noteworthy that a study showed that LPS-induced sickness behavior was blocked only if IL-1 $\beta$, IL- 6 , and TNF- $\alpha$ were antagonized simultaneously [46].

This facilitation in recovery from LPS-induced sickness has been observed in various nutritional and pharmacological interventions [5,47-49] and may be of particular importance when considering conditions where an exaggerated response is elicited during a primed inflammatory state, such as in overexpressing transgenic animals $[9,11]$, prion disease [6], and aging
$[7,8,10]$. We have previously demonstrated that aged animals display an exaggerated neuroinflammatory and sickness behavior response after activation of the peripheral immune system [7] and it appears that primed microglia are responsible for this exacerbated phenotype $[13,44,50]$. We and others have shown interventions that are anti-inflammatory are able to ameliorate the exaggerated cytokine response in the brain as well as the mal-adaptive behavioral response that results from peripheral infection [5,24,47-49,51]. Based on the data obtained from this study, it is possible that sgp130 will abrogate the prolonged LPS-induced alterations in sickness behavior, cognition, as well as exaggerated IL-6 levels exhibited in aged mice.

\section{Conclusion}

Studies have highlighted the potential therapeutic role of sgp130 in treating inflammation; it has been shown to suppress the severity of experimentally-induced arthritis, modulate leukocyte trafficking, and mitigate the effects of colitis and colon cancer $[18,40,52-54]$. The current study is the first to extend the body of literature and show the effectiveness of sgp130 in inhibiting IL-6 signaling in cells of the CNS and in brains of animals. The present results suggest that the use of sgp130 as an inhibitor of the IL-6 pathway in an array of inflammatory conditions, from arthritis to neuroinflammatory disorders, may mitigate IL- 6 expression and have a beneficial effect on behavioral responses.

\section{List of abbreviations}

(AP-1): Activator Protein-1; (AEBSF): 4-(2-Aminoethyl) benzenesulfonyl fluoride hydrochloride; (APC): Allophycocyanin; (ANOVA): Analysis of variance; (BCA): Bicinchoninic acid; (BSA): Bovine serum albumin; (CNS): Central nervous system; (CREB): CAMP response element-binding; (DMEM): Dulbecco's modified eagle's medium; (EDTA): Ethylene diamine tetraacetic acid; (EGTA): Ethylene glycol tetraacetic acid; (ELISA): Enzyme-linked immmunosorbent assay; (FITC): Fluorescein isothiocyanate; (FBS): Fetal bovine serum; (HBSS): Hank's balanced salt solution; (HEPES): 4-(2-hydroxyethyl)-1-

piperazineethanesulfonic acid; (HRP): Horseradish peroxidise; (ICV): Intracerebroventricular; (i.p.): Intraperitoneal; (NFKB): Nuclear factor kappa B; (PE): R-Phycoerthrin; (PMSF): Phenylmethylsulfonyl fluoride; (SAS): Statistical Analysis Systems; (SEM): Standard error of the mean; (SDS): Sodium dodecyl sulphate; (TLR4): Toll-like receptor-4; and (tyr): Tyrosine.

\section{Acknowledgements}

This research was supported by NIH grant, R01-AG16710 to R.W.J. M.D.B. is supported by NIH diversity supplement SR01-AG16710. 


\section{Authors' contributions}

MDB was involved in research experimentation, completion of statistical analysis, and writing of the manuscript. NLS assisted with experimentation and data analysis. RWJ directed all aspects of this research project including experimental design, research experimentation, completion of statistical analysis, and writing of the manuscript. All authors have read and approved the final version of the manuscript.

\section{Competing interests}

The authors declare that they have no competing interests.

Received: 26 February 2011 Accepted: 19 May 2011 Published: 19 May 2011

\section{References}

1. SF Maier, LE Goehler, M Fleshner, LR Watkins, The role of the vagus nerve in cytokine-to-brain communication. Neuroimmunomodulation. $\mathbf{8 4 0}$ 289-300 (1998)

2. N Quan, Immune-to-brain signaling: How important are the blood-brain barrier-independent pathways? Molecular Neurobiology. 37(2-3):142-152 (2008). doi:10.1007/s12035-008-8026-z

3. RM Ransohoff, VH Perry, Microglial Physiology: Unique Stimuli, Specialized Responses. Annual Review of Immunology. 27, 119-145 (2009). doi:10.1146/ annurev.immunol.021908.132528

4. KW Kelley, RM Bluthe, R Dantzer, JH Zhou, WH Shen, RW Johnson, SR Broussard, Cytokine-induced sickness behavior. Brain Behavior and Immunity. 17, S112-S118 (2003). doi:10.1016/S0889-1591(02)00077-6

5. J Abraham, RW Johnson, Central inhibition of interleukin-1 beta ameliorates sickness behavior in aged mice. Brain Behavior and Immunity. 23(3):396-401 (2009). doi:10.1016/j.bbi.2008.12.008

6. Ml Combrinck, VH Perry, C Cunningham, Peripheral infection evokes exaggerated sickness behaviour in pre-clinical murine prion disease. Neuroscience. 112(1):7-11 (2002). doi:10.1016/S0306-4522(02)00030-1

7. JP Godbout, J Chen, J Abraham, AF Richwine, BM Berg, KW Kelley, RW Johnson, Exaggerated neuroinflammation and sickness behavior in aged mice after activation of the peripheral innate immune system. Faseb Journal. 19(7):1329-+ (2005)

8. Y Huang, CJ Henry, R Dantzer, RW Johnson, JP Godbout, Exaggerated sickness behavior and brain proinflammatory cytokine expression in aged mice in response to intracerebroventricular lipopolysaccharide. Neurobiology of Aging. 29(11):1744-1753 (2008). doi:10.1016/j. neurobiolaging.2007.04.012

9. IL Campbell, CR Abraham, E Masliah, P Kemper, JD Inglis, MBA Oldstone, L Mucke, Neurologic disease induced in transgenic mice by cerebral overexpression of Interleukin-6. Proceedings of the National Academy of Sciences of the United States of America. 90(21):10061-10065 (1993). doi:10.1073/pnas.90.21.10061

10. J Chen, JB Buchanan, NL Sparkman, JP Godbout, GG Freund, RW Johnson, Neuroinflammation and disruption in working memory in aged mice after acute stimulation of the peripheral innate immune system. Brain Behavior and Immunity. 22(3):301-311 (2008). doi:10.1016/j.bbi.2007.08.014

11. CJ Heyser, E Masliah, A Samimi, IL Campbell, LH Gold, Progressive decline in avoidance learning paralleled by inflammatory neurodegeneration in transgenic mice expressing interleukin 6 in the brain. Proceedings of the National Academy of Sciences of the United States of America. 94(4):1500-1505 (1997). doi:10.1073/pnas.94.4.1500

12. MA Mines, CJ Yuskaitis, MK King, E Beurel, RS Jope, GSK3 Influences Social Preference and Anxiety-Related Behaviors during Social Interaction in a Mouse Model of Fragile X Syndrome and Autism. Plos One. 5, 3 (2010)

13. NL Sparkman, RW Johnson, Neuroinflammation Associated with Aging Sensitizes the Brain to the Effects of Infection or Stress. Neuroimmunomodulation. 15(4-6):323-330 (2008). doi:10.1159/000156474

14. NL Sparkman, JB Buchanan, JRR Heyen, J Chen, JL Beverly, RW Johnson, Interleukin-6 facilitates lipopolysaccharide-induced disruption in working memory and expression of other proinflammatory cytokines in hippocampal neuronal cell layers. Journal of Neuroscience. 26(42):10709-10716 (2006). doi:10.1523/JNEUROSCI.3376-06.2006

15. PC Heinrich, I Behrmann, G Muller-Newen, F Schaper, L Graeve, Interleukin6-type cytokine signalling through the gp130/Jak/STAT pathway. Biochemical Journal. 334, 297-314 (1998)
16. T Kishimoto, S Akira, T Taga, IL-6 receptor and mechanism of signal transduction. International Journal of Immunopharmacology. 14(3):431-438 (1992). doi:10.1016/0192-0561(92)90173-I

17. S Rosejohn, PC Heinrich, Soluble receptors for cytokines and growth factors - generation and biological function. Biochemical Journal. 300, 281-290 (1994)

18. SA Jones, PJ Richards, J Scheller, S Rose-John, IL-6 transsignaling: The in vivo consequences. Journal of Interferon and Cytokine Research. 25(5):241-253 (2005). doi:10.1089/jir.2005.25.241

19. T Jostock, J Mullberg, S Ozbek, R Atreya, G Blinn, N Voltz, M Fischer, MF Neurath, S Rose-John, Soluble gp130 is the natural inhibitor of soluble interleukin-6 receptor transsignaling responses. European Journal of Biochemistry. 268(1):160-167 (2001). doi:10.1046/j.1432-1327.2001.01867.x

20. S Diehl, M Rincon, The two faces of IL-6 on Th1/Th2 differentiation. Molecular Immunology. 39(9):531-536 (2002). doi:10.1016/50161-5890(02) 00210-9

21. J Mudter, MF Neurath, IL-6 signaling in inflammatory bowel disease: Pathophysiological role and clinical relevance. Inflammatory Bowel Diseases. 13(8):1016-1023 (2007). doi:10.1002/ibd.20148

22. S Jang, KW Kelley, RW Johnson, Luteolin reduces IL-6 production in microglia by inhibiting JNK phosphorylation and activation of AP-1. Proceedings of the National Academy of Sciences of the United States of America. 105(21):7534-7539 (2008). doi:10.1073/pnas.0802865105

23. Y Zorina, R lyengar, KD Bromberg, Cannabinoid 1 receptor and interleukin-6 receptor together induce integration of protein kinase and transcription factor signaling to trigger neurite outgrowth. Journal of Biological Chemistry. 285(2):1358-1370 (2010). doi:10.1074/jbc.M109.049841

24. CJ Henry, Y Huang, A Wynne, M Hanke, J Himler, MT Bailey, JF Sheridan, JP Godbout, Minocycline attenuates lipopolysaccharide (LPS)-induced neuroinflammation, sickness behavior, and anhedonia. Journal of Neuroinflammation. 5 (2008)

25. J Abraham, S Jang, JP Godbout, J Chen, KW Kelley, R Dantzer, RW Johnson, Aging sensitizes mice to behavioral deficits induced by central HIV-1 gp 120 . Neurobiology of Aging. 29(4):614-621 (2008). doi:10.1016/j. neurobiolaging.2006.11.002

26. BM Berg, JP Godbout, KW Kelley, RW Johnson, alpha-Tocopherol attenuates lipopolysaccharide-induced sickness behavior in mice. Brain Behavior and Immunity. 18(2):149-157 (2004). doi:10.1016/S0889-1591(03)00113-2

27. CP Krzyszton, NL Sparkman, RW Grant, JB Buchanan, SR Broussard, J Woods, RW Johnson, Exacerbated fatigue and motor deficits in interleukin-10deficient mice after peripheral immune stimulation. American Journal of Physiology-Regulatory Integrative and Comparative Physiology. 295(4): R1109-R1114 (2008). doi:10.1152/ajpregu.90302.2008

28. P Marz, U Otten, S Rose-John, Neural activities of IL-6-type cytokines often depend on soluble cytokine receptors. European Journal of Neuroscience. 11(9):2995-3004 (1999). doi:10.1046/j.1460-9568.1999.00755.x

29. B Schobitz, G Pezeshki, T Pohl, U Hemmann, PC Heinrich, F Holsboer, J Reul, Soluble Interleukin-6 (IL-6) receptor augments central effects of IL-6 in vivo. Faseb Journal. 9(8):659-664 (1995)

30. A Dreuw, S Radtke, S Pflanz, BE Lippok, PC Heinrich, HM Hermanns, Characterization of the signaling capacities of the novel gp130-like cytokine receptor. Journal of Biological Chemistry. 279(34):36112-36120 (2004). doi:10.1074/jbc.M401122200

31. T Taga, T Kishimoto, gp130 and the interleukin-6 family of cytokines. Annual Review of Immunology. 15, 797-819 (1997). doi:10.1146/annurev. immunol.15.1.797

32. SA Jones, S Rose-John, The role of soluble receptors in cytokine biology: the agonistic properties of the sIL-6R/LL-6 complex. Biochimica Et Biophysica Acta-Molecular Cell Research. 1592(3):251-263 (2002). doi:10.1016/S0167-4889(02)00319-1

33. R Dantzer, RM Bluthe, G Gheusi, S Cremona, S Laye, P Parnet, KW Kelley, Molecular basis of sickness behavior. in Molecular Mechanisms of Fever, ed. by Kluger MJ, Bartfai T, Dinarello CA 856, 132-138 (1998)

34. H Mizuguchi, H Mizuno, K Yasukawa, T Ishiguro, K Fukui, T Imanaka, M Takagi, Enhanced signal transduction by a directly fused protein of interleukin-6 and its receptor. Journal of Bioscience and Bioengineering. 91(3):299-304 (2001). doi:10.1263/jbb.91.299

35. S Nancey, N Hamzaoui, D Moussata, I Graber, I Bienvenu, B Flourie, Serum interleukin-6, soluble interleukin-6 receptor and Crohn's disease activity. Digestive Diseases and Sciences. 53(1):242-247 (2008). doi:10.1007/s10620007-9849-6 
36. N Laflamme, S Rivest, Toll-like receptor 4: the missing link of the cerebral innate immune response triggered by circulating gram-negative bacterial cell wall components. Faseb Journal. 15(1):155-163 (2001). doi:10.1096/fj.000339com

37. B Modrell, JW Liu, H Miller, M Shoyab, LIF and OSM directly interact with a soluble form of gp130, the IL-6 receptor signal-transducing subunit. Growth Factors. 11(2):81-91 (1994). doi:10.3109/08977199409001050

38. B Coles, CA Fielding, S Rose-John, J Scheller, SA Jones, VB O'Donnell, Classic interleukin-6 receptor signaling and interleukin-6 trans-signaling differentially control angiotensin II-dependent hypertension, cardiac signal transducer and activator of transcription-3 activation, and vascular hypertrophy in vivo. American Journal of Pathology. 171(1):315-325 (2007). doi:10.2353/ajpath.2007.061078

39. RM MCLoughlin, BJ Jenkins, D Grail, AS Williams, CA Fielding, CR Parker, M Ernst, N Topley, SA Jones, IL-6 trans-signaling via STAT3 directs T cell infiltration in acute inflammation. Proceedings of the National Academy of Sciences of the United States of America. 102(27):9589-9594 (2005). doi:10.1073/pnas.0501794102

40. PJ Richards, MA Nowell, S Horiuchi, RM McLoughlin, CA Fielding, S Grau, N Yamamoto, M Ehrmann, S Rose-John, AS Williams., et al, Functional characterization of a soluble gp130 isoform and its therapeutic capacity in an experimental model of inflammatory arthritis. Arthritis and Rheumatism. 54(5):1662-1672 (2006). doi:10.1002/art.21818

41. ML Block, L Zecca, JS Hong, Microglia-mediated neurotoxicity: uncovering the molecular mechanisms. Nature Reviews Neuroscience. 8(1):57-69 (2007). doi:10.1038/nrn2038

42. GW Kreutzberg, Microglia: A sensor for pathological events in the CNS Trends in Neurosciences. 19(8):312-318 (1996). doi:10.1016/0166-2236(96) 10049-7

43. SF Maier, LR Watkins, Cytokines for psychologists: Implications of bidirectional immune-to-brain communication for understanding behavior, mood, and cognition. Psychological Review. 105(1):83-107 (1998)

44. JP Godbout, BM Berg, KW Kelley, RW Johnson, alpha-Tocopherol reduces lipopolysaccharide-induced peroxide radical formation and interleukin-6 secretion in primary murine microglia and in brain. Journal of Neuroimmunology. 149(1-2):101-109 (2004). doi:10.1016/j. jneuroim.2003.12.017

45. JP Godbout, GM Berg, C Krzyszton, RW Johnson, alpha-Tocopherol attenuates NF kappa B activation and pro-inflammatory cytokine production in brain and improves recovery from lipopolysaccharideinduced sickness behavior. Journal of Neuroimmunology. 169(1-2):97-105 (2005). doi:10.1016/j.jneuroim.2005.08.003

46. AH Swiergiel, AJ Dunn, The roles of IL-1, IL-6, and TNF alpha in the feeding responses to endotoxin and influenza virus infection in mice. Brain Behavior and Immunity. 13(3):252-265 (1999). doi:10.1006/brbi.1999.0565

47. J Abraham, RW Johnson, Consuming a Diet Supplemented with Resveratrol Reduced Infection-Related Neuroinflammation and Deficits in Working Memory in Aged Mice. Rejuvenation Research. 12(6):445-453 (2009). doi:10.1089/rej.2009.0888

48. BM Berg, JP Godbout, J Chen, KW Kelley, RW Johnson, alpha-tocopherol and selenium facilitate recovery from lipopolysaccharide-induced sickness in aged mice. Journal of Nutrition. 135(5):1157-1163 (2005)

49. AF Richwine, JP Godbout, BM Berg, J Chen, J Escobar, DK Millard, RW Johnson, Improved psychomotor performance in aged mice fed diet high in antioxidants is associated with reduced ex vivo brain interleukin-6 production. Brain Behavior and Immunity. 19(6):512-520 (2005). doi:10.1016/ j.bbi.2004.12.005

50. SM Ye, RW Johnson, Increased interleukin-6 expression by microglia from brain of aged mice. Journal of Neuroimmunology. 93(1-2):139-148 (1999). doi:10.1016/S0165-5728(98)00217-3

51. J Saebyeol, RN Dilger, RW Johnson, Luteolin inhibits microglia and alters hippocampal-dependent spatial working memory in aged mice. Journal of Nutrition 140(10):1892-1898 (2010). 140 (110). doi:10.3945/jn.110.123273

52. Q Chen, WC Wang, R Bruce, H Li, DM Schleider, MJ Mulbury, MD Bain, PK Wallace, H Baumann, SS Evans, Central role of IL-6 receptor signaltransducing chain gp130 in activation of L-selectin adhesion by fever-range thermal stress. Immunity. 20(1):59-70 (2004). doi:10.1016/S1074-7613(03) 00358-3

53. CA Fielding, RM McLoughlin, L McLeod, CS Colmont, M Najdovska, D Grail, M Ernst, SA Jones, N Topley, BJ Jenkins, IL-6 regulates neutrophil trafficking during acute inflammation via STAT3. Journal of Immunology. 181(3):2189-2195 (2008)

54. R Atreya, S Finotto, J Mudter, J Mullberg, T Jostock, M Holtmann, T Kishimoto, PR Galle, S Rose-John, MF Neurath, Blockade of IL-6 transsignaling abrogates established experimental colitis in mice by suppression of $\mathrm{T}$ cell resistance against apoptosis. Gastroenterology. 118(4):4803 (2000)

doi:10.1186/1742-2094-8-54

Cite this article as: Burton et al:: Inhibition of interleukin- 6 transsignaling in the brain facilitates recovery from lipopolysaccharideinduced sickness behavior. Journal of Neuroinflammation 2011 8:54.

\section{Submit your next manuscript to BioMed Central and take full advantage of:}

- Convenient online submission

- Thorough peer review

- No space constraints or color figure charges

- Immediate publication on acceptance

- Inclusion in PubMed, CAS, Scopus and Google Scholar

- Research which is freely available for redistribution 